\title{
Exploring the Rooting Behaviour of BRRI (Bangladesh Rice Research Institute) Rice Cultivars
}

\author{
Mohammad Sayedul Islam ${ }^{*}$, Md. Ibne Saad Sikder Titas ${ }^{\#}$ \\ Department of Biochemistry and Molecular Biology, University of Chittagong, Chittagong, Bangladesh \\ Email: *sayedbmb@yahoo.com
}

How to cite this paper: Islam, M.S. and Titas, Md.I.S.S. (2021) Exploring the Rooting Behaviour of BRRI (Bangladesh Rice Research Institute) Rice Cultivars. American Journal of Plant Sciences, 12, 518-535. https://doi.org/10.4236/ajps.2021.124034

Received: March 8, 2021

Accepted: April 11, 2021

Published: April 14, 2021

Copyright $\odot 2021$ by author(s) and Scientific Research Publishing Inc. This work is licensed under the Creative Commons Attribution International License (CC BY 4.0).

http://creativecommons.org/licenses/by/4.0/

\section{(c) (i) Open Access}

\begin{abstract}
Rice (Oryza sativa L.) is the main staple cereal crops for half of the world's population which is predicted to exceed 9 billion by the 2050. Rice production needs to be doubled to meet the future demand of rice eating countries. To ensure the food security of growing population, sustainable rice production is needed. To achieve the expected yield, better understanding of the rice root systems will be required. A panel of rice cultivars, collected from Bangladesh Rice Research Institute (BRRI) were assessed through two established screening methods. Deep and shallow rooted cultivars were identified through hydroponic screening and soil filled rhizotron method. In hydroponic screening method, one way analysis of variance (ANOVA) revealed $99.13 \%$ variation explained by the genotype $(\mathrm{P}<0.001)$. At the same time, ANOVA revealed $73.37 \%$ variation explained by the genotype in soil filled glass rhizotron method $(\mathrm{P}<0.001)$. When comparing the data of root traits obtained from hydroponic and rhizotron experiments, 4 cultivars were identified as deep rooted cultivars, which would be very promising cultivars for rice breeding programmes in drought prone regions.
\end{abstract}

\section{Keywords}

Rice, Root, Screening, Traits, Phenotyping, Hydroponic and Rhizotron

\section{Introduction}

Rice (Oryza sativa L.) is considered as a staple food crop and is consumed by more than half of the world's population [1]. More than 3.5 billion people feed on this domesticated crop [2] and $20 \%$ of their daily calories is provided by rice

*Corresponding author.

"Both authors contributed equally to this work. 
[3]. In Asia, more than $90 \%$ of the world's rice is produced and consumed [4]. Rice production has to be raised to approximately 160 million tons by 2050 from the current level of 100 million tons to ensure food security for the increasing global population [5]. To increase the production rate, it is necessary to overcome challenges such as the yield plateau, diminishing resources, and changing climate [6].

The root systems of plants have a vital role in the acquisition of nutrients and water and have therefore been a focus of research activity aimed largely at understanding their function and improving crop yields [7] [8]. This is particularly relevant within the context of climate change and unsustainable resource use in agriculture where, for example, shallow roots might be required for improved efficiency in acquiring soil phosphorus [9] or deep roots might be required to access stored soil water [10]. Roots are, however, difficult to study since they are underground and are intrinsically complex because of the spatial and temporal variability in distribution and activity. There is a need to develop and validate methods that allow assessment of root system architecture (RSA), yet there are two conflicting drivers to be considered in such methods. One is increased precision that allows a more accurate description of the location and activity of the root system in both space and time. The other is increased throughput that will allow root phenotyping to manage numbers of genotypes that match the impressive ability of molecular techniques to genetically characterize those [11].

Breeding programs have traditionally focused on the aboveground plant parts (forage, seed or grain production) for the generation of food, feed and fiber. Breeders aim to develop improved cultivars that can tolerate a variety of abiotic stress conditions such as drought or flooding. These approaches include selection of individuals with improved plant growth characteristics such as grain or biomass yield, seed production, leaf surface area, the number of tillers and disease resistance. Strategies to implement "root breeding" require the identification of the underground root traits that enable a plant to more efficiently utilize water and nutrients in different environments [12]. Multiple studies have identified links between root traits and crop productivity [13] [14] including performance under drought [15] and grain yield [16]. The key roles of roots as part of plant development have sparked renewed interest in understanding the molecular mechanisms that control RSA in crops [17] [18] [19] [20] [21].

Drought avoidance is one of the most important strategies for maintaining crop yields in water-limited environments. Drought avoidance is most often attributed to root phenes that support better water capture and transport to the shoot [9] [22]. Investigating the architectural and anatomical phenes that contribute to rooting depth is essential for improving crop performance under drought stress [9].

Uga and his coworkers have been cloned and characterized a quantitative trait locus (QTL) for root growth angle in rice, named DEEPER ROOTING 1 (DROI) [15]. DRO1 functions downstream of the auxin signaling pathway and controls the gravitropic curvature in rice roots. The authors also developed Dro1-NIL, carrying a functional allele of $D R O 1$ derived from the deep-rooting cultivar Kinandang Patong (a traditional tropical japonica upland cultivar of Philippine ori- 
gin) in the genetic background of the shallow-rooting parent variety IR64 (a modern lowland indica cultivar, widely grown in South and Southeast Asia), which has a non-functional allele of DRO1. Under upland conditions, Dro1-NIL showed deeper rooting than IR64, although the two lines did not show any marked differences in other root and shoot traits [15]. Under upland conditions with drought stress, Dro1-NIL maintained better grain filling and thus showed higher yield than IR64 because the plants avoided drought stress by collecting water from deep soil. This clearly demonstrated that deep rooting is a beneficial trait for stable rice production under drought conditions.

Since Weaver (1919) performed a pioneering investigation on rice root, great progress has been made in rice root biology. It is well known that the functions of absorption and support of root system are an important guarantee for biological yield and grain yield of rice. Therefore, root traits have been claimed to be critical for increasing yield under soil-related stresses [23]. Root morphology and physiology are closely associated with the growth and development of aboveground part of plant [24]. A panel of 26 upland and lowland varieties were screened through hydroponic systems. The data suggested that the upland varieties showed longer rooting systems than the lowland varieties and upland varieties possess a pronounced and thicker rooting systems. Comparing the data with IRRI's drought score in early vegetative stage, the plants with long bigger and thicker rooting systems are more drought resistance than those with the shallow and thinner root systems [25]. Hydroponic has been widely used to evaluate root system development and for the identification of QTLs. Price and Tomos (1997) used a hydroponic system and mapped QTLs for eight root growth characteristics (e.g. maximum root length, root volume, root thickness) [25]. Al-Shugeairy et al. (2014) assessed root system characteristics in a subset of herbicide assessed rice plants using soil filled chambers called rhizotrons [27].

The main objective of this project is to explore the rooting behavior of the BRRI rice cultivars. The ultimate objectives of the project is to identify the promising cultivars by using hydroponic system and rhizotron systems as screening techniques of root systems of Aus, Aman and Boro cultivars collected from the Bangladesh Rice Research Institute (BRRI).

\section{Materials and Methods}

\subsection{Setting up Hydroponic System}

Plants are grown in soil free water system i.e. hydroponic with plastic box that are filled with Yoshida's nutrient solution and germinated seedlings were transferred in black seedling trays that are well fitted with the top of each box. Data of root and shoot length has to be taken by upholding each tray containing vegetative seedlings. After 7 or 8 weeks the hydroponics can be harvested to assess the shoot and root length and root thickness. This technique has been used to assess a mapping population, sampling diversity at scales of 4 to 6 hydroponics at a time. 


\subsubsection{Plant Materials}

Three check varieties IR64, Black Gora and Azucena were included with eighteen accessions collected from Bangladesh Rice Research Institute (BRRI) for screening as follows:

1) Aus cultivars-BR 21, BRRI 42, BRRI 48.

2) Aman cultivars-BRRI 32, BRRI 30, BRRI 49, BRRI 51, BRRI 52, BR 22.

3) Boro cultivars-BR 19, BRRI 29, BRRI 50, BRRI 28, BR 3, BRRI 36, BR 14, BR 16, BRRI 60 .

\subsubsection{Hydroponic Screening for Visualizing Roots}

The experiment was set up on 14 December 2018. Four replicates including three check varieties and thirteen accessions were organized as a randomized complete block design. The all 16 accessions were tested in the hydroponic set up. Azucena, Black Gora and IR 64 were included with those accessions as check varieties.

Seeds were first surface sterilized by soaking with five times diluted domestic bleach $1 \%$ sodium chloro hypochlorite $(\mathrm{NaHClO} 3)$ for approximately 5 minutes and washed three times with tap water. Seeds were then germinated at $30^{\circ} \mathrm{C}$ for three days. Germinated seedlings were transferred in black seedling trays containing 84 wells ( $12 \times 7$ wells) with $55 \mathrm{~mm}$ deep and $12 \mathrm{~mm}$ diameter at the bottom and $40 \mathrm{~mm}$ on the top. Germinated seedlings were placed on the piece of a mesh $(15 \times 5 \mathrm{~mm})$ resting above the hole of a well. Each seedling tray was fitted in the $50 \mathrm{~L}$ plastic box $56 \mathrm{~cm}$ long, $36 \mathrm{~cm}$ wide and $29 \mathrm{~cm}$ deep. The empty wells were covered by the aluminum foil to prevent the entry of the light to the nutrient solution while the sides of the boxes were covered by plastic sheets that was white on the exterior and black on the interior. Plastic sheets were used to prevent algae formation upon light penetration. Aeration system was set up in the box. Each box filled with $50 \mathrm{~L}$ half strength Yoshida's nutrient solution (pH5.5) [26] for the first three weeks then full-strength nutrient solution for the final four weeks. Nutrient solutions were replaced twice a week and $\mathrm{pH}$ was adjusted daily. The experiment was conducted in the Department of Biochemistry and molecular Biology laboratory, University of Chittagong, humidity was maintained $70 \%$ and the temperature was $25^{\circ} \mathrm{C}$ to $28^{\circ} \mathrm{C}$ throughout the experiment. The supplementary lights were supplied $120 \mu \mathrm{Mm}-2 \mathrm{~s}-1$ (PAR) $12 \mathrm{hrs}$. a day. The maximum root and shoot length of each plant were recorded weekly for five weeks (Figure 1).

\subsection{Setting up Rhizotron System}

For Rhizotron screening, all accessions with check varieties were tested in using soil-filled glass rhizotrons for visualizing roots. Plants are grown in the glass sided rhizotrons that are filled with soil and inclined at $15^{\circ}$. Photographs can be taken and non-destructive assessment (visual) made of root traits such as root angle and depth whenever required. After 6 or 7 weeks the rhizotron can be harvested. 


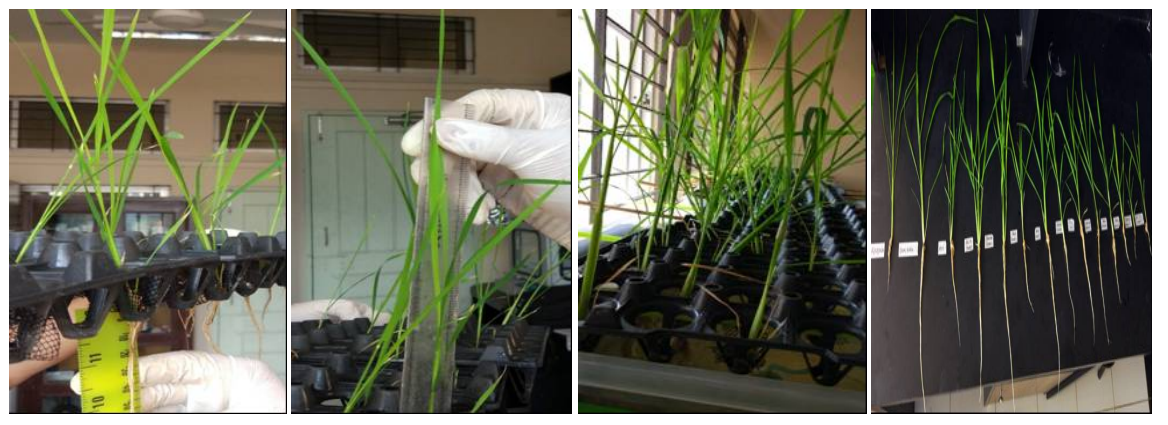

Figure 1. Experimental set up of hydroponic system of root screening and measurement of root and shoot length (From left to right).

\subsubsection{Plant Materials}

Two check varieties IR64 and Azucena were included with six accessions collected from Bangladesh Rice Research Institute (BRRI)—BR 3 (Boro), BR 14 (Boro), BR 19 (Boro), BRRI 60 (Boro), BR 22 (Aman), BRRI 32 (Aman) for screening.

\subsubsection{Materials Used}

1) Sheet of $4 \mathrm{~mm}$ thick glass cut to $1200 \mathrm{~mm} \times 300 \mathrm{~mm}$.

2) Sandy loam soil sieved using a coarse sieve (approximately $5 \mathrm{~mm}$ mesh) to remove stone and large clumps.

3) Drip irrigation system (available in gardening stores).

4) Supplies using duct tape, two lengths of $15 \mathrm{~mm}$ thick and $100 \mathrm{~mm}$ long wood, bottle tops custom made metal chute to guide soil and chemicals for nutrient solution.

\subsubsection{Rhizotron Set up and Irrigation}

The experiment was set up on 8 April 2019. Four replicates including two check varieties and six accessions were organized as a randomized complete block design and set for rhizotron screening. Plants were grown for 42 days and water was withheld from day 39 so that daily water use in the last 3 days could be assessed. Two glass sheets are selected, at least one of which clean on both sides. One is placed on a work surface with two of four edges slightly overhanging. Two lengths of $15 \mathrm{~mm}$ thick wood are placed on the top of the first sheet, a 15 $\mathrm{mm}$ bottle top is placed at the top and the bottom of the glass as spacers and the second sheet of glass were placed over the top. Duct tape is used to join the two sheets of glass together at the overhanging edges. The sheets are turned so that remaining long edges are overhanging and that is then sealed with duct tape. Three of the four sides are therefore completely sealed with duct tape. The empty rhizotron are set vertical, a single strip of duct tape is wound right around at a depth of about $300 \mathrm{~mm}$ from the bottom, and two length of wood are removed. The bottle tops prevent the glass from together and empty rhizotron can therefore be stacked and waiting for filling. The bottle top can be removed at a later date during the soil filling process. The bottle top at the bottom must remain in the rhizotron. The empty rhizotron is stood upon a soft support such as expanded polystyrene sheet and sieved soil is then encouraged into the rhizotron 
using the dustpan and custom-made guide. When the rhizotron is nearly full, the upper bottle top can be removed. When full, the rhizotron is lifted and then gently dropped onto the support, causing the soil level to drop $10-15 \mathrm{~cm}$ due to packing of the soil. The rhizotron is refilled, gently dropped once more and refilled to within $5 \mathrm{~mm}$ of the top for a final time. The force of the drop will affect the amount of soil used. The aim is to pack the soil sufficiently well to prevent slumping of the soil when it is watered but not so much that it splits the tape, or create impedance to the roots. The latter can be roughly assessed by pushing a sharpened pencil into the soil. If it is difficult to push, the roots will probably also find it difficult. Once filled the rhizotron should be weighed with aim to have each rhizotron the same weight. Typically, the rhizotrons weigh $13 \mathrm{~kg}$ and contain about $7 \mathrm{~kg}$ of wet soil. A small drainage hole should be made at each side at the bottom using an implement such as a sharpened pencil. Typically, rhizotrons are placed in stacks of eight and are learned at an angle of $15^{\circ}$ to encourage roots to grow on the lower face. The exposed face of the first stack was backed with an insulation sheet to reduce heat exchange and prevent light penetration. Insulation was placed over the front of the stacks and an irrigation system was installed. This should supply water equally to each rhizotron and apply it slowly (to avoid soil clumping). Typically, an irrigation rate of $40 \mathrm{ml} / \mathrm{min}$ is used. This can be used to supply nutrients and water as required.

Each rhizotron is labeled on the lower sheet so that in a photograph of that side (where roots are most visible) the identity of the rhizotron can be seen. Typically, two seeds were sown on each rhizotron, and thinned to one when they have emerged. Watering was typically done three times a week with $250 \mathrm{ml}$ of Yoshida's nutrient solution for the first 3 weeks, moving up to more frequent and larger volumes of nutrient and water as the plant grow reaching about 250 $\mathrm{ml}$ nutrient and $150 \mathrm{ml}$ of water every day when 6 weeks old. However, amounts will vary with the environment. Photograph of the lower side of each rhizotron can be taken when must be done in the dark to reduce reflection from the glass. Those can be done at night using spotlights at either side of the rhizotrons. On a weekly basis, shoot growth was monitored as height of the plant (length from the soil to the top of the longest leaf) while the length of the longest visible root and the number of the root that were passed 25, 50, 75 and $100 \mathrm{~cm}$ are recorded (Figure 2).

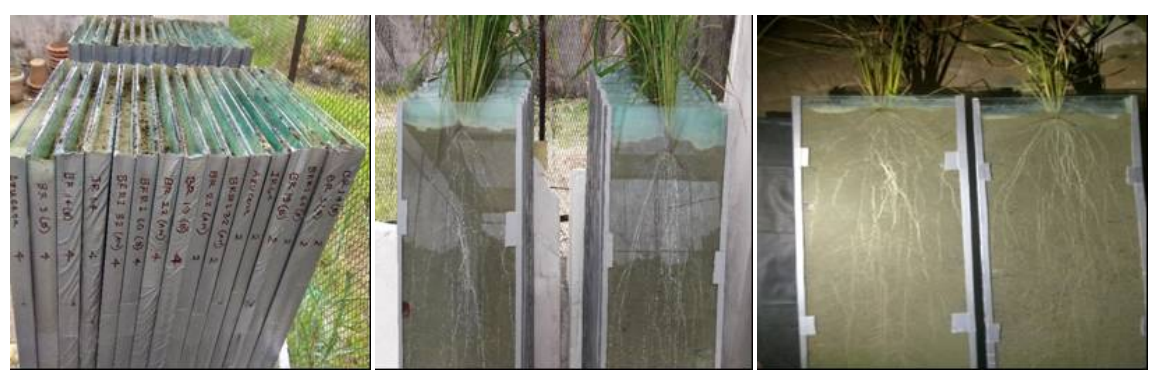

Figure 2. Experimental set up of rhizotron system of root screening. Seed kept for germination, stacks of rhizotron and 40 days old plants (From left to right). 


\subsubsection{Data Analysis}

Collected root and shoot traits data from hydroponic and rhizotron experiment, were analyzed by using Minitab version 17 . The data was first transformed to make the data normally distributed, then corrected for block effects and finally differences between cultivars assessed using ANOVA.

\section{Results and Discussion}

\subsection{Results}

\subsubsection{Hydroponic Screening}

The mean root length and shoot length increased in a linear fashion with time (Figure 3). Plants had a mean root length of $1.775 \mathrm{~cm}$ at day 26 which increased up to $26.025 \mathrm{~cm}$ at day 52 and had a mean shoot length of $16.52 \mathrm{~cm}$ at day 26 which increased up to $29.72 \mathrm{~cm}$ at day 52 . Shoot growth showed a greater increase from $7.85 \mathrm{~cm}$ at days 26 to $41.35 \mathrm{~cm}$ at day 52 . A total of 16 cultivars tested in the hydroponic experiment showed a great difference in root length and shoot length throughout the experiment. The maximum root length and shoot length of all genotypes at days 52 is shown in Figures 3-5.

The check variety Azucena had the highest root length while BRRI 32 Aman cultivar had the lowest root length at day 26 (Figure 6). Again, BR 3 cultivar had the highest root length while BRRI 48 Aus cultivar had the lowest root length at day 26 (Figure 7).

At Day 52, BRRI 60 Boro cultivar had the highest root length while BRRI 48 Aus cultivar had the lowest root length (Figure 8).

In case of shoot length analysis, Black Gora had the highest shoot length in $\mathrm{cm}$ at Day 26 while BRRI 36 Boro cultivar had the lowest shoot length in $\mathrm{cm}$ (Figure 9) At day 37, Black Gora had the highest shoot length and BRRI 48 Aus had the lowest shoot length (Figure 9) At day 52, these two again showed the highest and the lowest shoot lengths respectively (Figure 10, Figure 11).

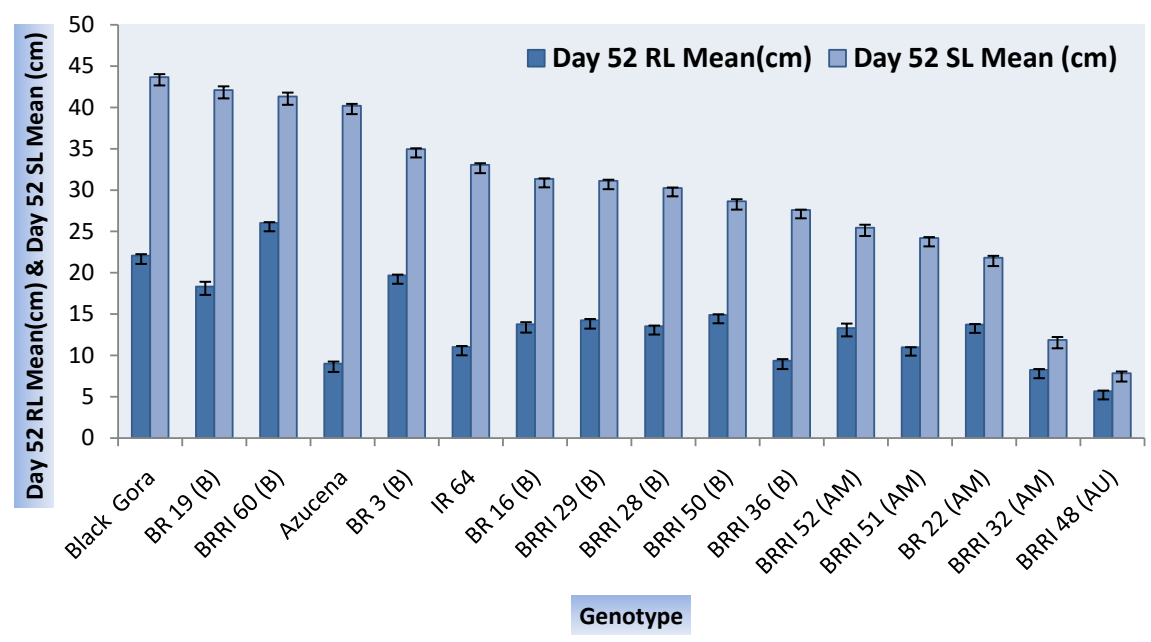

Figure 3. Root (deep blue) and shoot (light blue) length at day 52 of all 16 hydroponic genotypes in 2-D graphical figure. Error bar represents standard errors. 


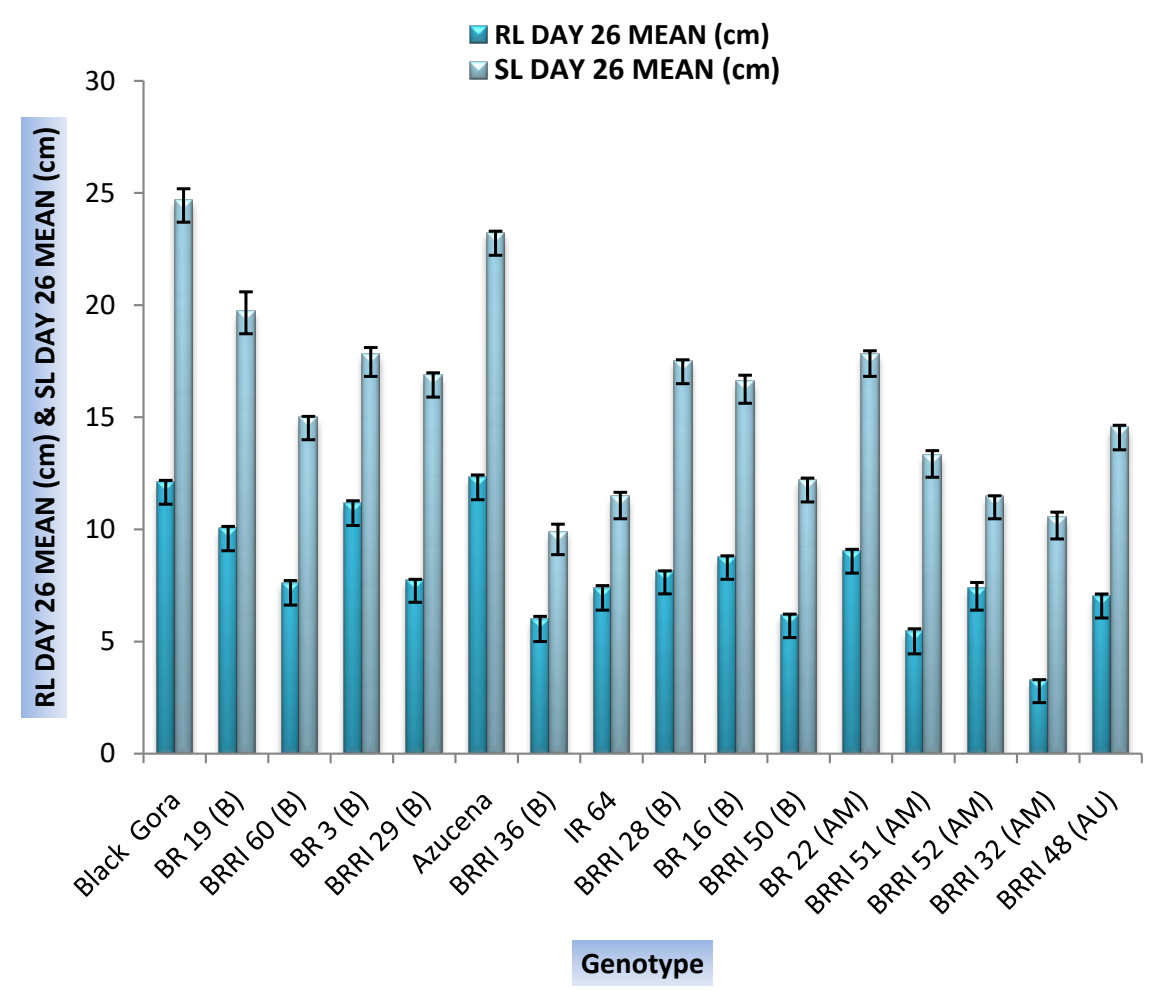

Figure 4. Root (deep blue) and shoot (light blue) length at day 26 of all 16 hydroponic genotypes in 2-D graphical figure. Error bar represents standard errors.

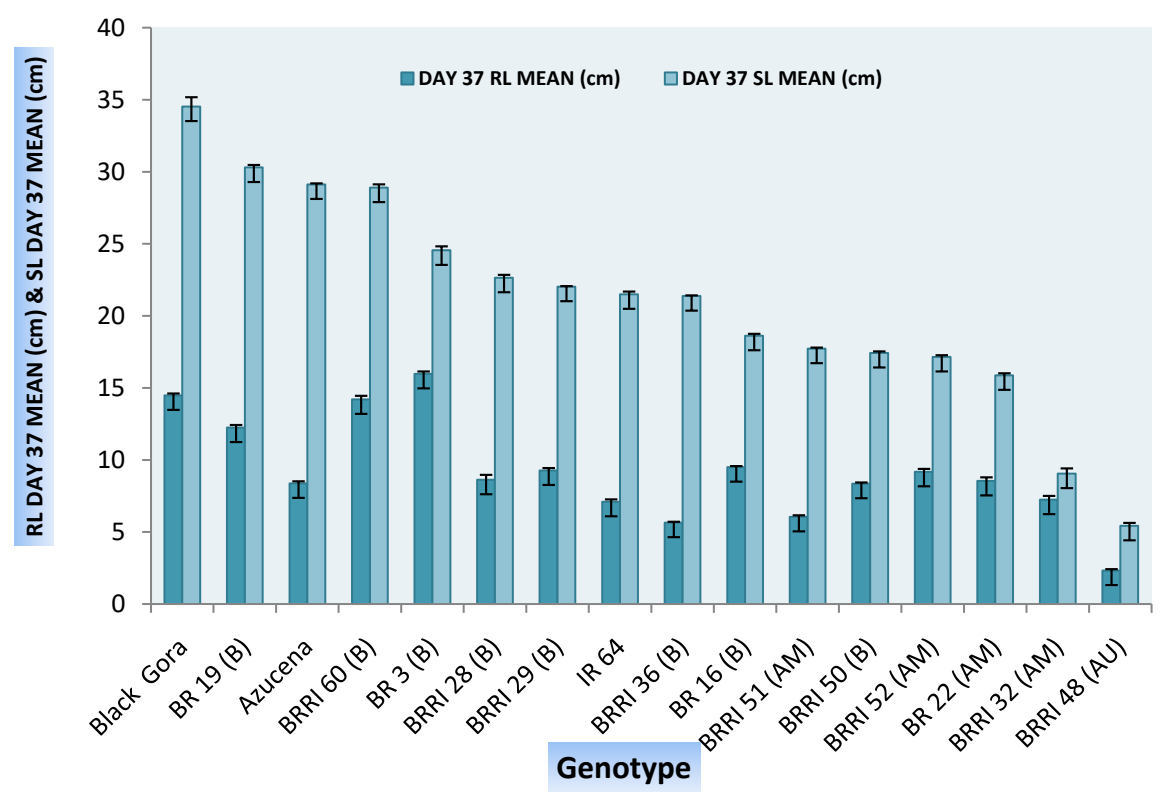

Figure 5. Root (deep blue) and shoot (light blue) length at day 37 of all 16 hydroponic genotypes in 2-D graphical figure. Error bar represents standard errors.

\subsubsection{Analysis of Genotypic Variations}

In case of root length analysis, significant variations were observed at all days of measurement and the proportion of variations explained by the genotypes were increased from day 26 to day 52 where it was highest at day 37 . That means the 


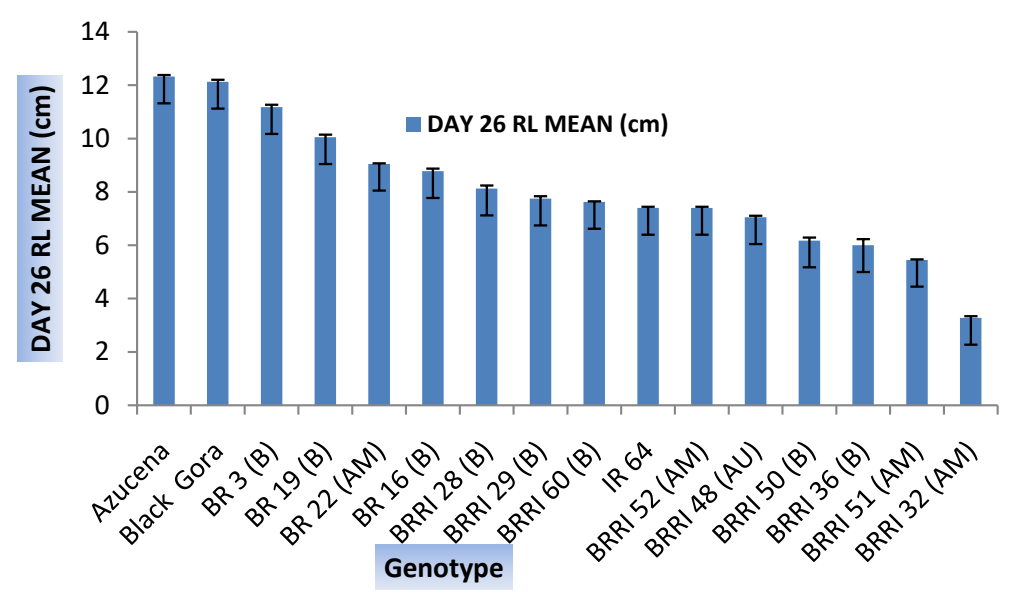

Figure 6. Root (deep blue) length in $\mathrm{cm}$. at day 26 of all 16 hydroponic genotypes in 2-D graphical figure. Error bar represents standard errors.

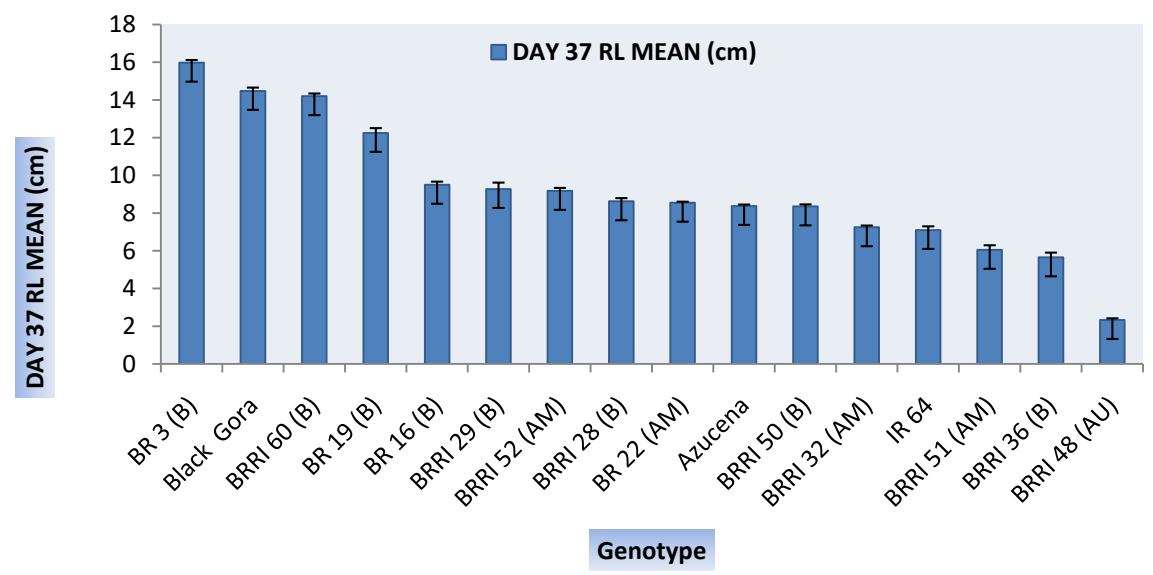

Figure 7. Root (deep blue) length in $\mathrm{cm}$. at day 37 of all 16 hydroponic genotypes in 2-D graphical figure. Error bar represents standard errors.

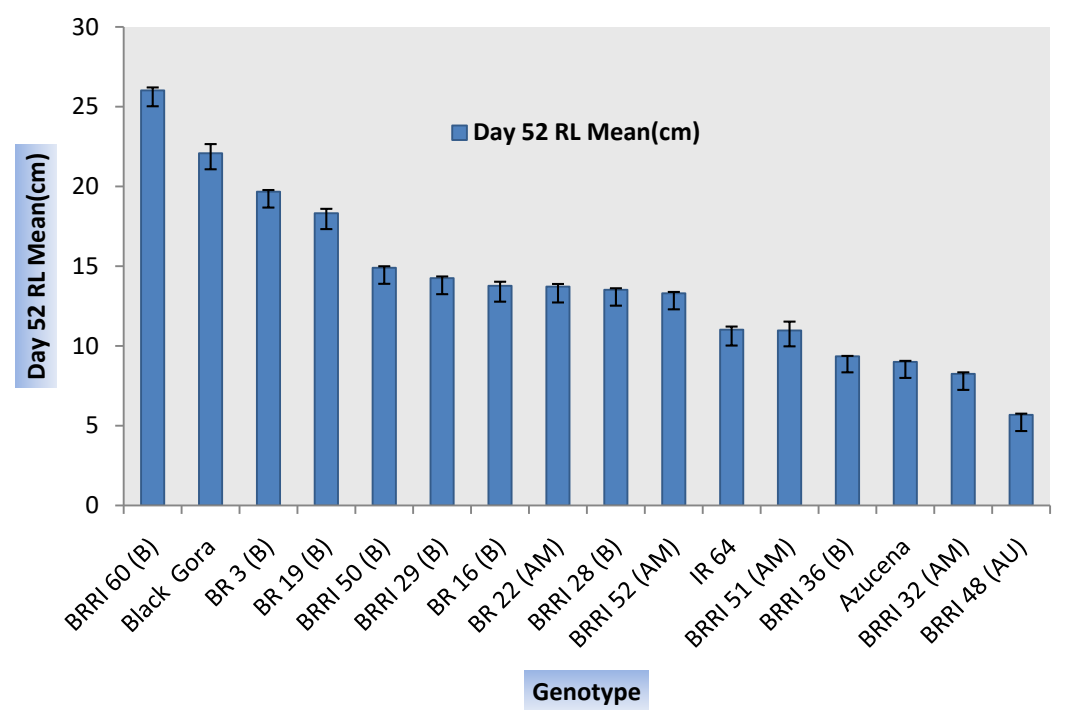

Figure 8. Root (deep blue) length in $\mathrm{cm}$. at day 52 of all 16 hydroponic genotypes in 2-D graphical figure. Error bar represents standard errors. 


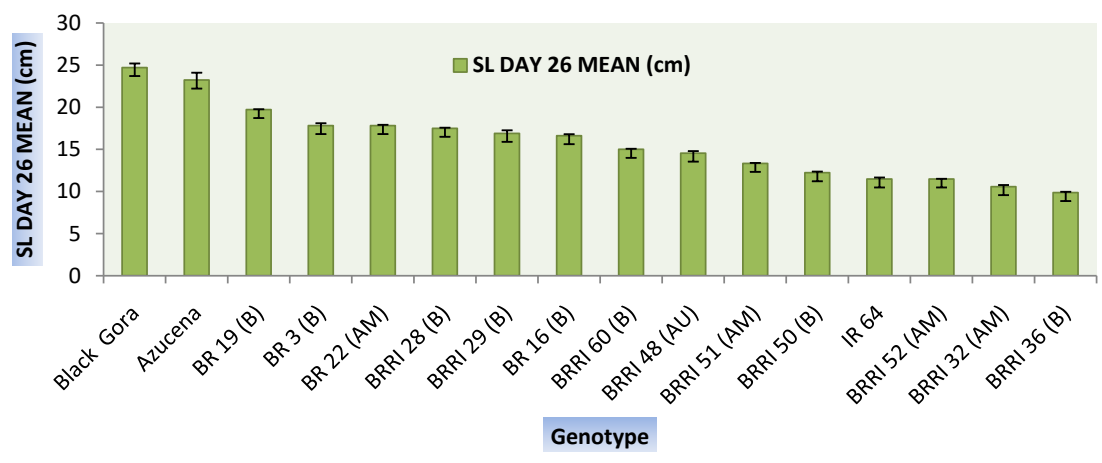

Figure 9. Shoot length in $\mathrm{cm}$. at day 26 of all 16 hydroponic genotypes in 2-D graphical figure. Error bar represents standard errors.

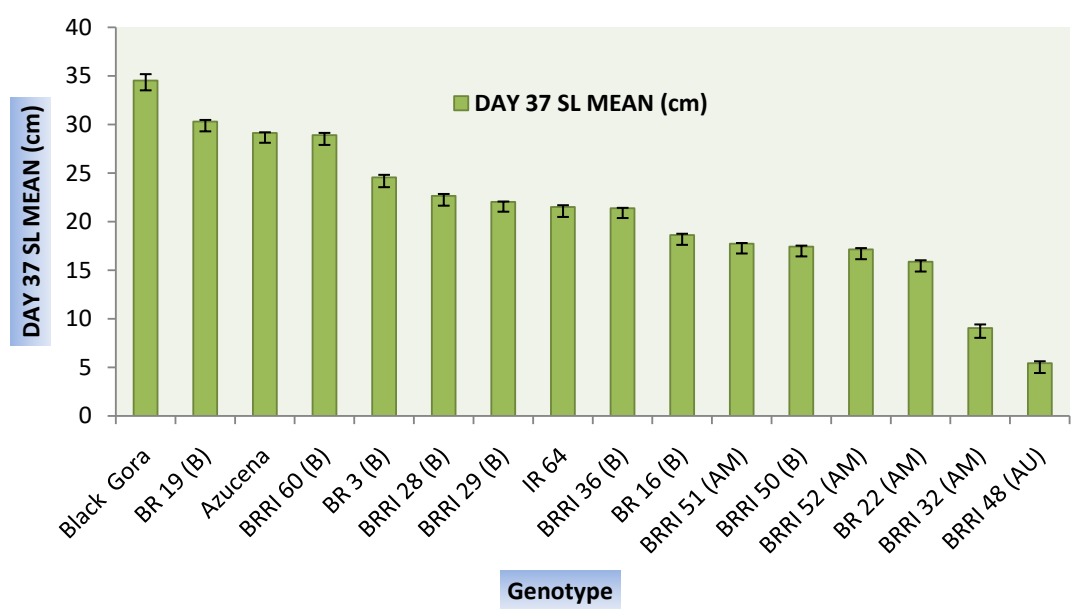

Figure 10. Shoot length in $\mathrm{cm}$. at day 37 of all 16 hydroponic genotypes in 2-D graphical figure. Error bar represents standard errors.

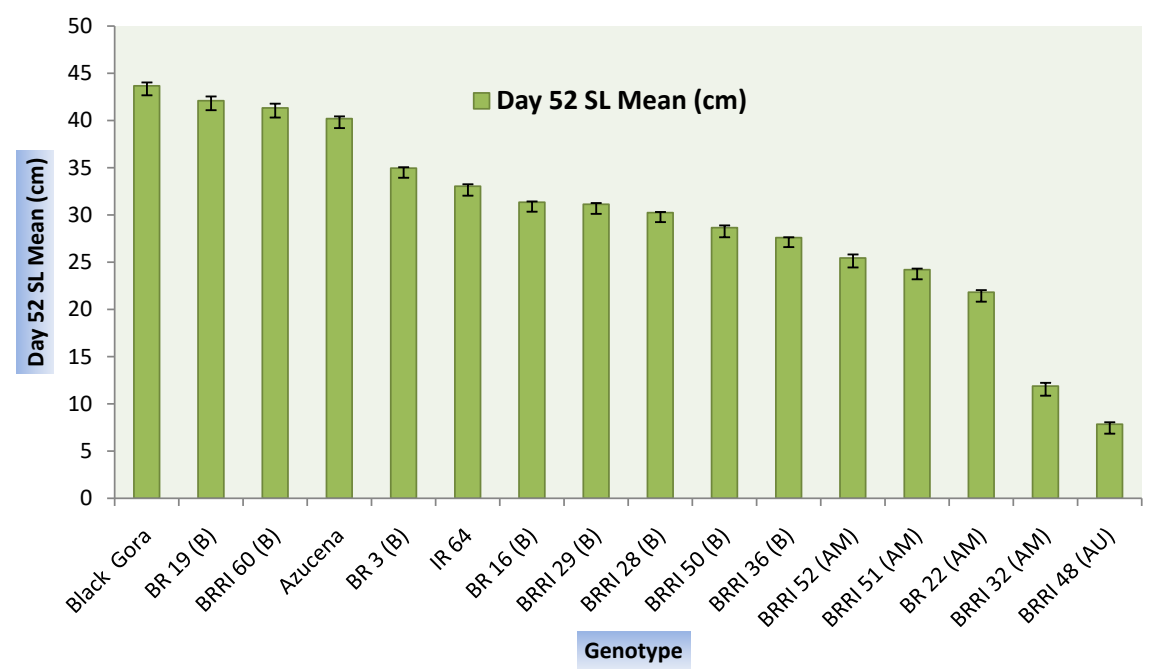

Figure 11. Shoot length in $\mathrm{cm}$. at day 52 of all 16 hydroponic genotypes in 2-D graphical figure. Error bar represents standard errors.

highest discrimination of root length was observed at day 37. Azucena, Black Gora, BR 3, BR 19, BR 16, BRRI 60 had the longest root on that day while IR64, 
BRRI 51, BRRI 36, had the shortest.

The maximum root length of days 37 ranges from $14 \mathrm{~cm}$ to $16 \mathrm{~cm}$ and Black Gora and BR3 were the highest and BRRI 36 and IR 64 were the lowest and at that time $58.27 \%$ variation explained by the genotype $(\mathrm{P}<0.001)$.

The data of root length and shoot length were recorded at 52 days after sowing (DAS) of hydroponic experiment having significant result $(\mathrm{P}<0.001)$. Black Gora, BRRI 60 and BR 3 had longest root length and IR 64, BRRI 51 and BRRI 36 had the shortest root length.

In the root length and shoot length data for three control varieties Azucena, Black Gora and IR64 (check varieties), significant variation was observed from day 5 to day 52 (DAS) and the proportion of variation explained by the genotypes were increased from day 5 to 52 (Figure 12, Figure 13).

\subsubsection{Rhizotron Screening}

In rhizotron screening method, the mean root length and shoot length in soil filled rhizotron increased in a linear fashion with time (Figure 14).

The maximum visible root length along with the shoot length $(\mathrm{cm})$ has shown in the Figures 14-16. In the same time maximum visible root and shoot length

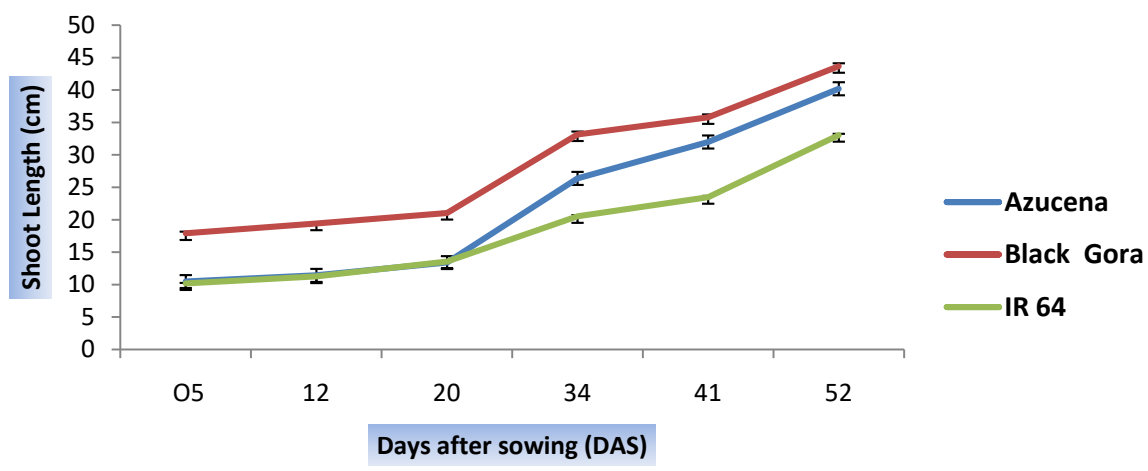

Figure 12. The increase in shoot length mean from 5 - 52 days after sowing for three check varieties (Azucena, Black Gora and IR64). Error bar represents standard errors.

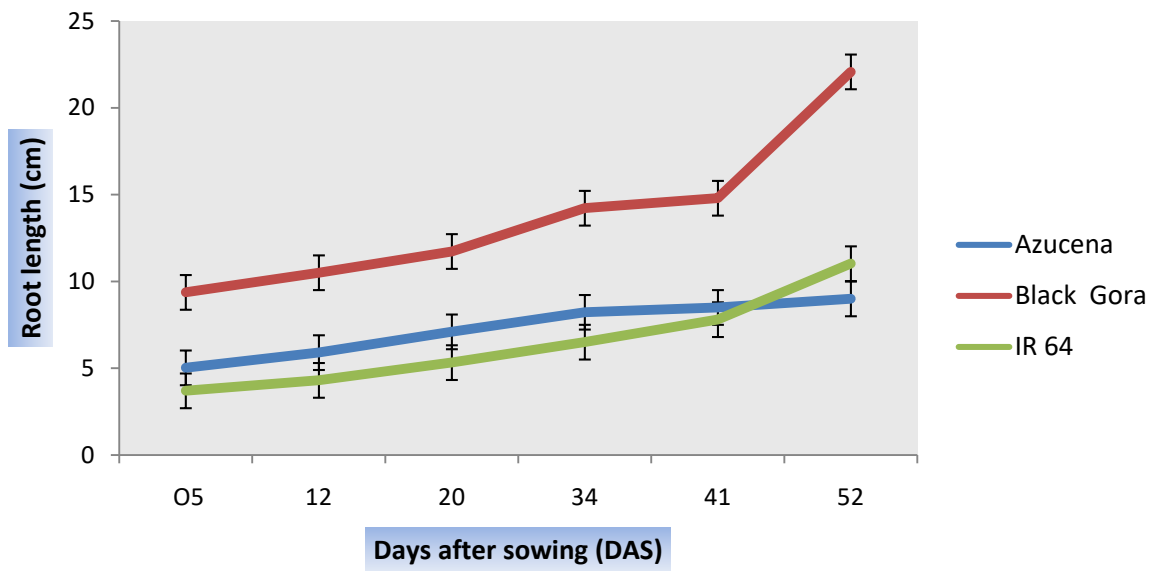

Figure 13. The increase in root length mean from 5 - 52 days after sowing for three check varieties (Azucena, Black Gora and IR64). Error bar represents standard errors. 


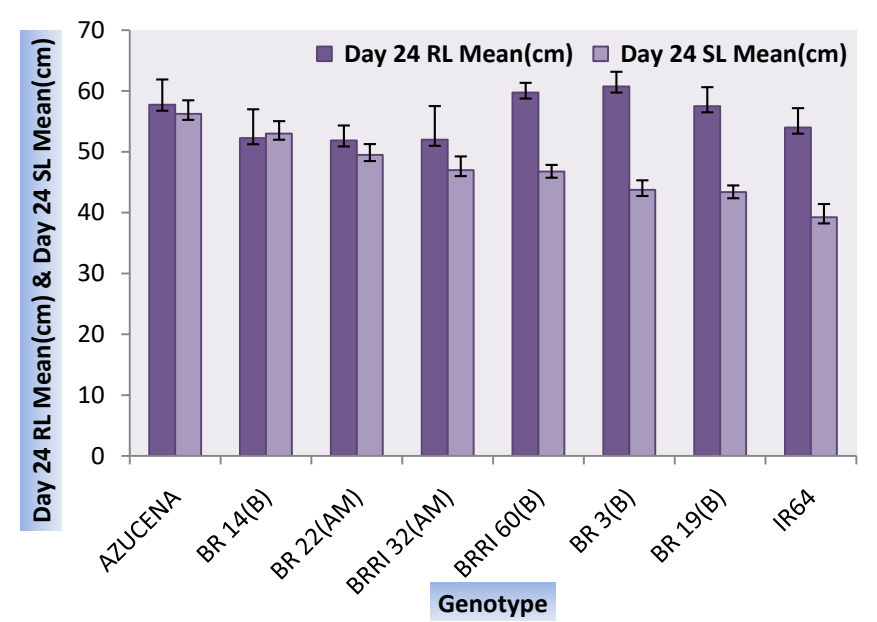

Figure 14. Root (deep color) and shoot (light color) length at day 24 of all 8 rhizotron genotypes in 2-D graphical figure. Error bar represents standard errors.

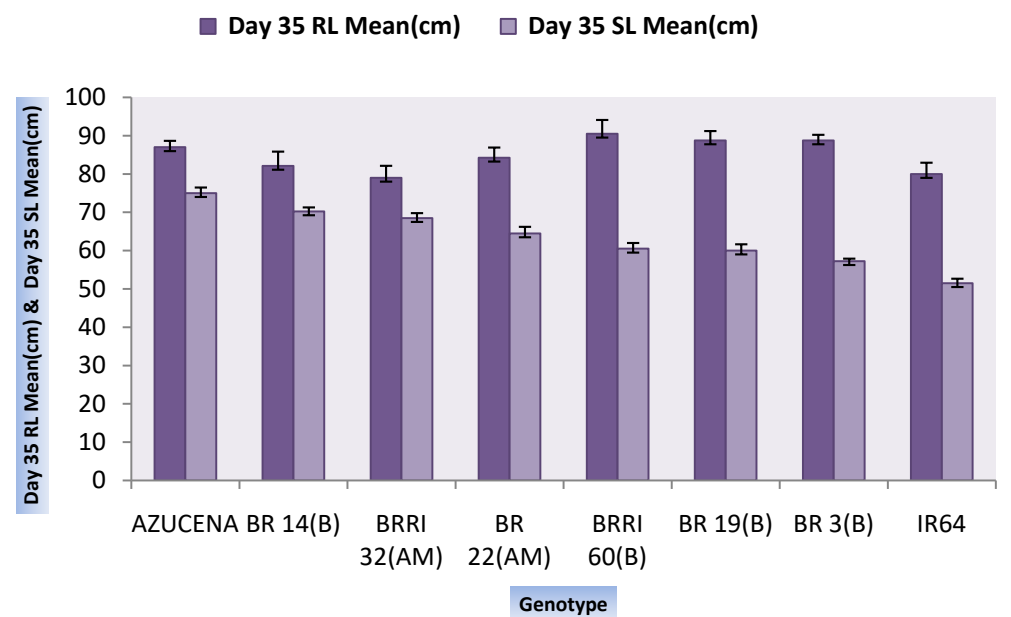

Figure 15. Root (deep color) and shoot (light color) length at day 35 of all 8 rhizotron genotypes in 2-D graphical figure. Error bar represents standard errors.

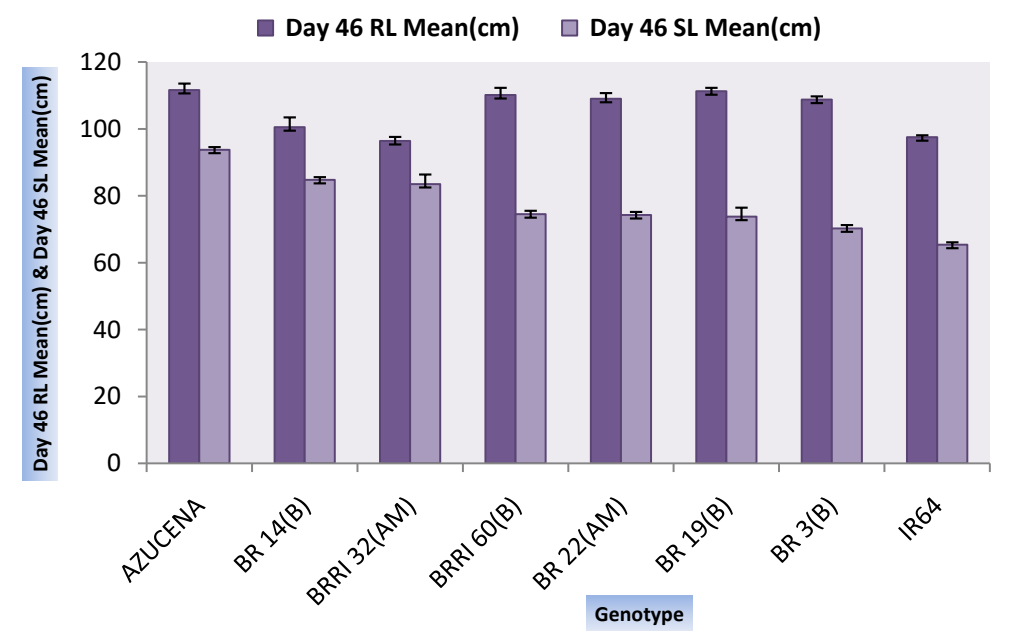

Figure 16. Root (deep color) and shoot (light color) length at day 46 of all 8 rhizotron genotypes in 2-D graphical figure. Error bar represents standard errors. 
data has shown individually in the Figures $17-22$ and the check varieties in the Figure 23, Figure 24.

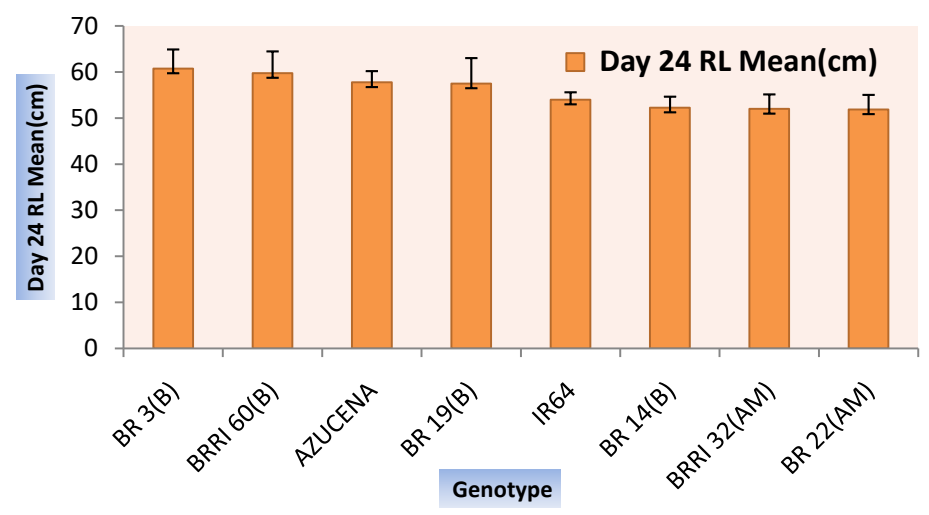

Figure 17. Root length at day 24 of all 8 rhizotron genotypes in 2-D graphical figure. Error bar represents standard errors.

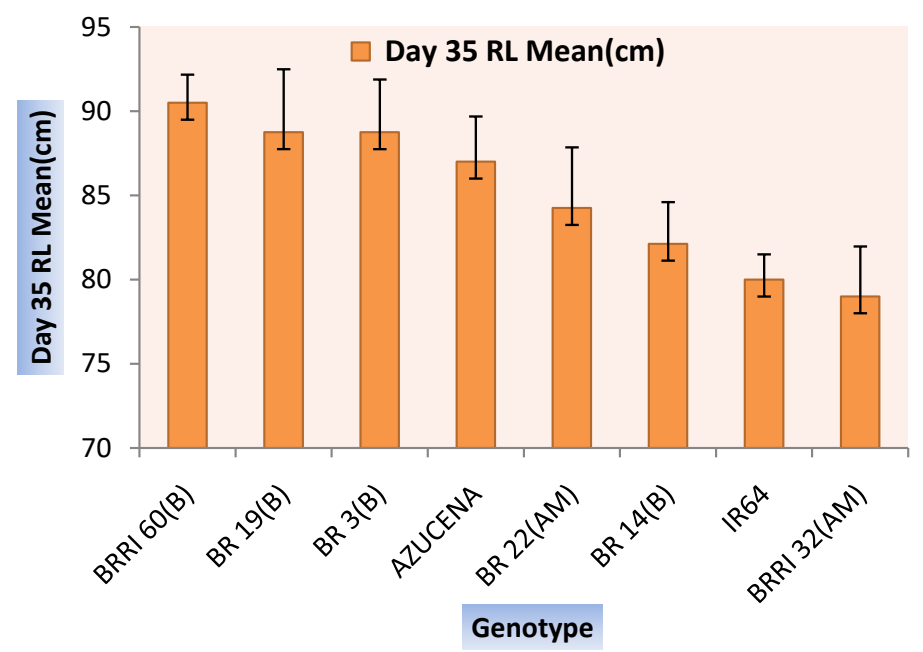

Figure 18. Root length at day 35 of all 8 rhizotron genotypes in 2-D graphical figure. Error bar represents standard errors.

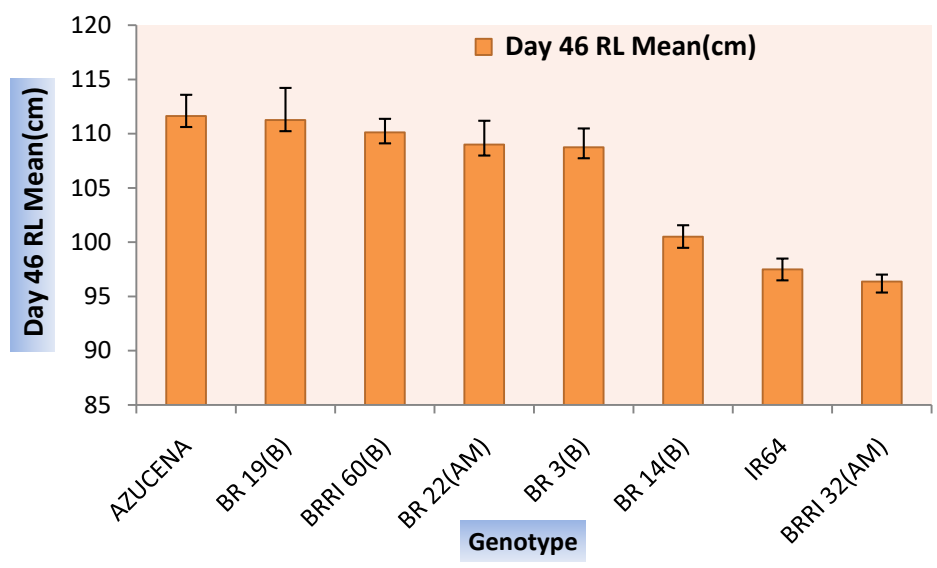

Figure 19. Root length at day 46 of all 8 rhizotron genotypes in 2-D graphical figure. Error bar represents standard errors. 


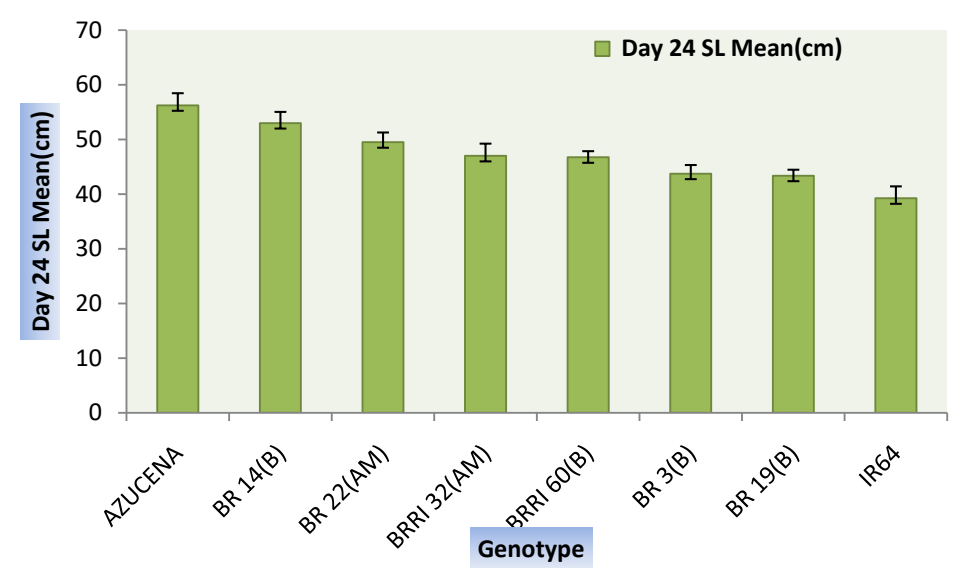

Figure 20. Shoot length at day 24 of all 8 rhizotron genotypes in 2-D graphical figure. Error bar represents standard errors.

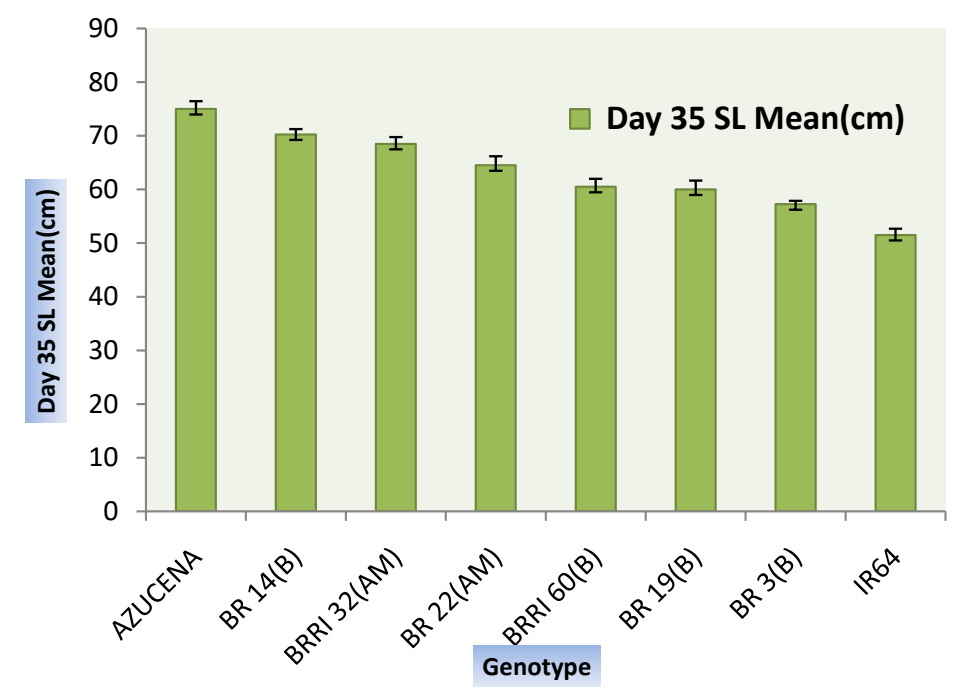

Figure 21. Shoot length at day 35 of all 8 rhizotron genotypes in 2-D graphical figure. Error bar represents standard errors.

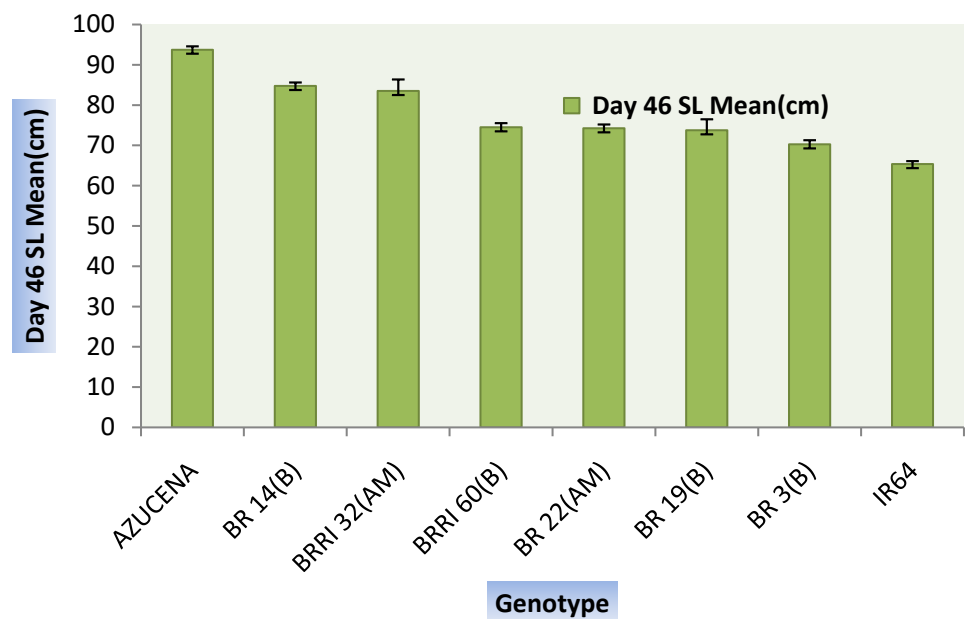

Figure 22. Shoot length at day 46 of all 8 rhizotron genotypes in 2-D graphical figure. Error bar represents standard errors. 


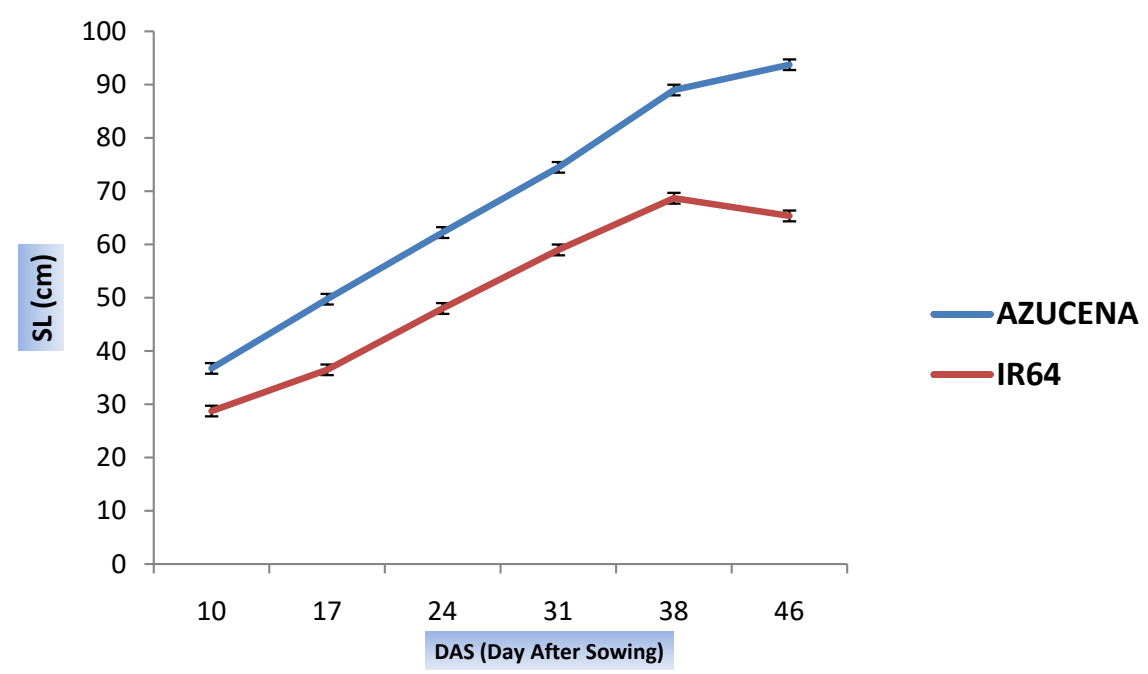

Figure 23. The increase in shoot length mean from 10 - 42 days after sowing for two check varieties (Azucena and IR64). Error bar represents standard errors.

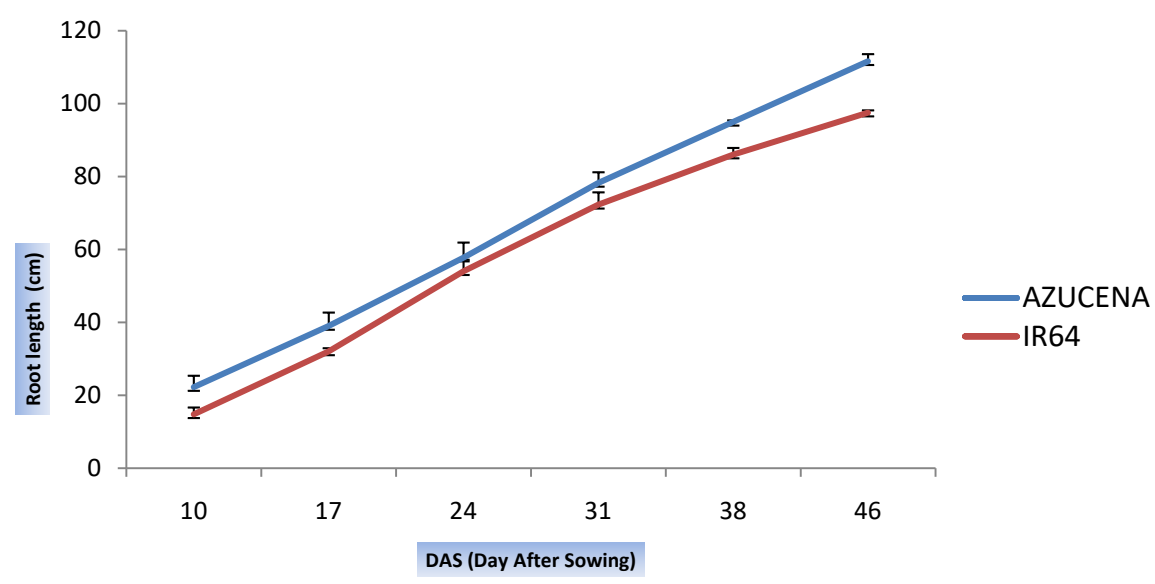

Figure 24. The increase in Root length mean from 10 - 42 days after sowing for two check varieties (Azucena and IR64). Error bar represents standard errors.

The maximum visible root length of the check varieties shows that Azucena had long with vertical axes and IR 64 had shallow rooted which follows the same pattern as previously detected data [27].

The maximum visible root length measured in the rhizotron experiment increased $110 \mathrm{~cm}$ at day 46 from $66 \mathrm{~cm}$ at day 24 . The proportion variation explained by genotypes for the maximum visible root length showed an increased pattern from day 24 to day 46 respectively. Among the landraces genotype BRRI 60, BR19 and BR3 had the longest visible root which were higher at all stages than the mean root length BR14 and BR32 had the shortest root systems (Figure 14).

One way analysis of variance (ANOVA) revealed $73.37 \%$ variation $(\mathrm{P}<0.001)$ explained by the genotype at 46 days after sowing (DAS) and three BBRI cultivars had the highest root length and two showed the shallow rooted cultivars.

When comparing the hydroponic root traits data with rhizotron, at least three 
BRRI cultivars BRRI 60 (Boro), BR 22 (Aman) and BR 3 (Boro) showed deep rooted cultivars in both soil (rhizotron) and liquid media(hydroponic).

\subsubsection{Screening of Check Variety}

Hydroponic screens have the advantage that the roots can be continually monitored for root growth, however after a period of time the roots become intertwine each other and the $\mathrm{pH}$ reduces rapidly [11]. Also, hydroponics is a non-soil based system, so if the roots respond in a solution system to how they would in a soil system could be an issue. Another screening method is rhizotrons, the main advantages are that the plants are grown in soil and that root angle information can be assessed. In addition stresses related to nutrients or water can be measured. Like hydroponics this system can be continually measured, however due to their 2D construction they do limit root growth in all natural directions as well as being a labour intensive screen, therefore reducing their use in high throughput screens.

Initially 16 accessions were assessed in hydroponic experiment. Significant variation was observed between genotypes which reflected the variation of rooting behavior of the genotypes. In rhizotron experiment, six cultivars along with two check varieties were screened. The deep rooted cultivars detected from the hydroponic experiment as for example, BRRI 32 and BRRI 60, also revealed the deep rooted as well in rhizotron experiment. Comparing the result of hydroponic and rhizotron methods BRRI 32 and BRRI 60 was surprising since it has already been shown deep rooted cultivars in different planting methods. This data already been reported in BRRI annual report 2015-16 [28]. Comparing the result of the other methods, hydroponic and rhizotron screening methods has given confidence for the tested of the cultivars.

\section{Conclusion}

The hydroponic and rhizotron data suggested that BRRI 60 has the deepest rooting systems and BRRI 48 is the shallow rooted systems than the other accessions tested in the screening method. In conclusion, the cultivars identified from this research project can then be further studied with the hope of harnessing the natural genetic diversity within rice to breed improved rice cultivars for drought prone regions.

\section{Acknowledgements}

The research was supported by research and publication cell University of Chittagong, Bangladesh.

\section{Conflicts of Interest}

The authors declare no conflicts of interest regarding the publication of this paper.

\section{References}

[1] FAO Rice Market Monitor (RMM). 
http://www.fao.org/economic/est/publications/rice-publications/rice-market-monit or-rmm/en

[2] Caicedo, A.L., Williamson, S.H., Hernandez, R.D., Boyko, A., Fledel-Alon, A., York, T.L., Bustamante, C.D., et al. (2007) Genome-Wide Patterns of Nucleotide Polymorphism in Domesticated Rice. PLoS Genetics, 3, e163. https://doi.org/10.1371/journal.pgen.0030163

[3] IRRI Knowledge Bank. http://www.knowledgebank.irri.org/bmp.html

[4] Food and Agricultural Organization (2014). http://www.fao.org/fileadmin/templates/est/Commonmarketmonitoring/Rice/Docu ments/RiceProfileDec-06.pdf

[5] Ramanathan, V., Rahman, H., Subramanian, S., Nallathambi, J., Kaliyaperumal, A., Manickam, S. and Muthurajan, R. (2018) OsARD4 Encoding an Acireductone Dioxygenase Improves Root Architecture in Rice by Promoting Development of Secondary Roots. Scientific Reports, 8, Article No. 15713.

https://doi.org/10.1038/s41598-018-34053-y

[6] Ray, D.K., Mueller, N.D., West, P.C. and Foley, J.A. (2013) Yield Trends Are Insufficient to Double Global Crop Production by 2050. PLoS ONE, 8, e66428.

https://doi.org/10.1371/journal.pone.0066428

[7] De Dorlodot, S., Forster, B., Pages, L., Price, A., Tuberosa, R. and Draye, X. (2007) Root System Architecture: Opportunities and Constraints for Genetic Improvement of Crops. Trends in Plant Science, 12, 474-481.

https://doi.org/10.1016/j.tplants.2007.08.012

[8] Gowda, V.R., Henry, A., Yamauchi, A., Shashidhar, H.E. and Serraj, R. (2011) Root Biology and Genetic Improvement for Drought Avoidance in Rice. Field Crops Research, 122, 1-13. https://doi.org/10.1016/j.fcr.2011.03.001

[9] Lynch, J., Chimungu, J. and Brown, K. (2014) Root Anatomical Phenes Associated with Water Acquisition from Drying Soil: Targets for Crop Improvement. Journal of Experimental Botany, 65, 6155-6166. https://doi.org/10.1093/jxb/eru162

[10] Henry, A., Gowda, V.R., Torres, R.O., McNally, K.L. and Serraj, R. (2011) Variation in Root System Architecture and Drought Response in Rice (Oryza sativa): Phenotyping of the OryzaSNP Panel in Rainfed Lowland Fields. Field Crops Research, 120, 205-214. https://doi.org/10.1016/j.fcr.2010.10.003

[11] Shrestha, R., Al-Shugeairy, Z., Al-Ogaidi, F., Munasinghe, M., Radermacher, M., Vandenhirtz, J. and Price, A.H. (2014) Comparing Simple Root Phenotyping Methods on a Core Set of Rice Genotypes. Plant Biology, 16, 632-642.

https://doi.org/10.1111/plb.12096

[12] García-Morales, S., Trejo-Téllez, L.I., Gómez-Merino, F.C., Espinosa-Victoria, D., Herrera-Cabrera, E.B., Tavitas-Fuentes, L. and Hernández-Aragón, L. (2011) Physiological Response of Rice Plants Growing under Osmotic Stress in Hydroponics. II International Symposium on Soilless Culture and Hydroponics, Vol. 947, 401-408. https://doi.org/10.17660/ActaHortic.2012.947.52

[13] Kell, D.B. (2011) Breeding Crop Plants with Deep Roots: Their Role in Sustainable Carbon, Nutrient and Water Sequestration. Annals of Botany, 108, 407-418.

https://doi.org/10.1093/aob/mcr175

[14] Hufnagel, B., de Sousa, S.M., Assis, L., Guimaraes, C.T., Leiser, W., Azevedo, G.C., Negri, B., Larson, B.G., Shaff, J.E. and Pastina, M.M. (2014) Duplicate and Conquer: Multiple Homologs of PHOSPHORUS-STARVATION TOLERANCE1 Enhance Phosphorus Acquisition and Sorghum Performance on Low-Phosphorus Soils. Plant Physiology, 166, 659-677. https://doi.org/10.1104/pp.114.243949 
[15] Uga, Y., Sugimoto, K., Ogawa, S., Rane, J., Ishitani, M., Hara, N., Inoue, H., et al. (2013) Control of Root System Architecture by DEEPER ROOTING 1 Increases Rice Yield under Drought Conditions. Nature Genetics, 45, 1097. https://doi.org/10.1038/ng.2725

[16] Narayanan, S., Mohan, A., Gill, K.S. and Prasad, P.V. (2014) Variability of Root Traits in Spring Wheat Germplasm. PLoS ONE, 9, e100317. https://doi.org/10.1371/journal.pone.0100317

[17] Meister, R., Rajani, M., Ruzicka, D. and Schachtman, D.P. (2014) Challenges of Modifying Root Traits in Crops for Agriculture. Trends in Plant Science, 19, 779-788. https://doi.org/10.1016/j.tplants.2014.08.005

[18] Furbank, R.T. and Tester, M. (2011) Phenomics-Technologies to Relieve the Phenotyping Bottleneck. Trends in Plant Science, 16, 635-644.

https://doi.org/10.1016/j.tplants.2011.09.005

[19] Rascher, U., Blossfeld, S., Fiorani, F., Jahnke, S., Jansen, M., Kuhn, A.J., Matsubara, S., Märtin, L.L., Merchant, A. and Metzner, R. (2011) Non-Invasive Approaches for Phenotyping of Enhanced Performance Traits in Bean. Functional Plant Biology, 38, 968-983. https://doi.org/10.1071/FP11164

[20] York, L.M., Nord, E.A. and Lynch, J.P. (2013) Integration of Root Phenes for Soil Resource Acquisition. Frontiers in Plant Science, 4, 355. https://doi.org/10.3389/fpls.2013.00355

[21] Fiorani, F. and Schurr, U. (2013) Future Scenarios for Plant Phenotyping. Annual Review of Plant Biology, 64, 267-291. https://doi.org/10.1146/annurev-arplant-050312-120137

[22] Clark, L., Cope, R., Whalley, W., et al. (2002) Root Penetration of Strong Soil in Rainfed Lowland Rice: Comparison of Laboratory Screens with Field Performance. Field Crops Research, 76, 189-198. https://doi.org/10.1016/S0378-4290(02)00039-4

[23] Lynch, J.P. (2007) Roots of the Second Green Revolution. Australian Journal of Botany, 55, 493-512. https://doi.org/10.1071/BT06118

[24] Yang, J. (2011) Relationships of Rice Root Morphology and Physiology with the Formation of Grain Yield and Quality and the Nutrient Absorption and Utilization. Scientia Agricultura Sinica, 44, 36-46.

[25] Price, A.H., Tomos, A.D. and Virk, D.S. (1997) Genetic Dissection of Root Growth in Rice (Oryza sativa L.) I: A Hydroponic Screen. Theoretical and Applied Genetics, 95, 132-142. https://doi.org/10.1007/s001220050541

[26] Yoshida, S., Forno, D.A., Lock, J.H. and Gomez, K.A. (1976) A Laboratory Manual for the Physiological Studies of Rice. IRRI, Manila, 61-66.

[27] Al-shugeairy, Z., Islam, M.S., Shrestha, R., Al-Ogaidi, F., Norton, G.J. and Price, A.H. (2014) High Throughput Screening of Rooting Depth in Rice Using Buried Herbicide. Annals of Applied Biology, 165, 96-107.

https://doi.org/10.1111/aab.12118

[28] http://brri.portal.gov.bd/BRRI_Annual_Report_15-16.pdf 